\title{
Estudo dos Perfís Compostos em Fibra de Vidro pelo Processo de Fabricação por Pultrusão Combinando as Vantagens do Plástico com a Madeira e o Aço
}

\section{Study of the Profiles Composed of Fiberglass by the Manufacturing Process of Pultrusion Combining the Advantages of Plastic with Wood and Steel}

Artigo

Original

\section{Original}

Paper

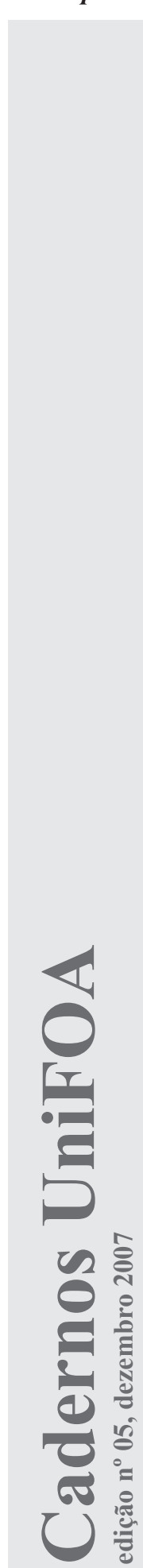

Alexandre José de Athayde Guimarães ${ }^{1}$

Palavras-chaves:

Madeira

Aço

Telhado

\begin{abstract}
Wood is, probably, the oldest construction material in use for building the structures of the canopies and roofs of buildings. The first applications of the metal profiles in canopies and roofs started in the nineteenth century. The plastic profiles reinforced with fibers appeared in the national market in the 80s in the twentieth century. However, the application of such profiles in PRF has not been significant if compared to the potential of the product. Besides, environmental consciousness developed in the ecologically correct society has limited the deforestation and prevented the felling of trees thus greatly reducing the offering of wood profiles in the housing construction market. For this reason, the truss in plastic profiles reinforced with fiberglass in canopies and roofs as well as the kinds of connection are the objectives of this article.
\end{abstract}

A madeira é, provavelmente, o material de construção mais antigo utilizado para compor as estruturas das coberturas e dos telhados das edificações. As primeiras aplicações dos perfis metálicos em coberturas e telhados são do século XIX. Os perfis em plástico reforçado com fibras surgiram no mercado nacional nos anos 80 do século XX. Entretanto, a aplicação de perfis em PRF tem sido insignificante face à potencialidade desse produto. Além disso, a consciência ambiental desenvolvida na sociedade ecologicamente correta tem limitado o desmatamento e impedido a derrubada de determinados para a utilização de treliças em perfis em plástico reforçado com fibras de vidro em coberturas e telhados, bem como esclarecer os tipos de ligações possíveis são os objetivos deste artigo.

Wood

Steel

Roof

\section{Key words:}

Steel

\section{Introdução}

As tradicionais estruturas em madeira têm apresentado problemas de deterioração, principalmente, em regiões litorâneas e industriais. Além disso, acrescente-se o elevado preço da madeira, devido a problemas ecológicos inerentes a extração deste tipo de material.

O aço, industrializado como perfil metálico, surgiu como alternativa à madeira. As primeiras aplicações em estrutura para coberturas e telhados datam do século XIX. Apesar de todo o desenvolvimento na fabricação do aço, este como material para construção civil, não venceu as restrições relacionadas à reduzida resistência aos ataques químicos, ao elevado custo de manutenção da obra e ao peso-próprio dos elementos estruturais na etapa de montagem.

Os perfis em plástico reforçado com fibra - PRF - surgiram no mercado nacional nos

${ }^{1}$ Mestre - Curso de Engenharia Civil / UniFOA 
anos 80. Apresentam reduzido peso-próprio, elevada resistência aos ataques químicos e de insetos, baixo custo de manutenção entre outras vantagens. Apesar disso, a aplicação de perfis em PRF tem sido insignificante face à potencialidade desse produto.

Este artigo mostra o potencial da aplicação das treliças em perfil de plástico reforçado com fibras de vidro para coberturas e telhados.

\section{Perfis em Plástico Reforçado com Fibra de Vidro}

Fiberglass é o nome genérico que se dá ao plástico reforçado com fibra de vidro. É um compósito, com duas fases distintas e visíveis a olho nu: as fibras e o plástico. As fibras, no caso, são feitas de filamentos de vidro, tão finos, que não ficam quebradiços, mas sim, flexíveis. O plástico pode ser termoplástico ou termofixo. Em nosso caso, é o termofixo, ou seja, não pode ser remodelado por calor ou qualquer outro processo. Uma vez curado, permanece nessa forma.

Atualmente, o plástico reforçado com fibra de vidro é utilizado na construção civil, na indústria automobilística, na indústria aeronáutica, nos aviões e em residências entre outros; vem substituindo os materiais tradicionais com vantagem, devido as suas versáteis características:

- Pode ser acabada em qualquer cor;

- Facilmente reparável quando danificada;

- Ótima estabilidade dimensional;

- Ótima relação resistência/peso;

- Mínima deterioração por intempéries;

- Pode receber aditivo antichama;

- Baixa expansão/contração sob mudanças térmicas.

Os perfis pultrudados são materiais compósitos em fibra-resina. São fabricados através do processo de pultrusão, que combina as vantagens do plástico e do metal. Em alguns materiais são utilizadas fibra de vidro, carbono, aramida ou fibras naturais com diferentes resinas termofixas, do tipo poliéster, estervinílica ou epóxi. Em algumas aplicações podemos utilizar resinas termoplásticas.

Vários produtos se valem das vantagens dos perfis pultrudados. $\mathrm{O}$ material é usado em estruturas para telhados, lajes para piso e teto e nas barras de reforço para substituição do aço existente na composição do concreto. A sua alta resistência à corrosão faz com que sejam usados como pisos pelo setor químico. Já tirantes se valem da sua resistência estrutural. Prédios também podem ser estruturados com esses perfis.

O material possui menor dilatação que o aço, por exemplo, e mantém características estruturais semelhantes a ele.

\subsection{Processo de Pultrusão}

O processo de pultrusão consiste no puxamento de fibras de vidro impregnadas por resina Poliéster através de um molde metálico aquecido. Inicialmente, as fibras de vidro são impregnadas pela resina líquida em banheiras apropriadas. Em seguida, o composto préimpregnado passa por formadores, que conferem ao material o formato aproximado da seção do perfil ou chapa. Ao passar pelo molde aquecido, o Poliéster sofre a transformação de líquido em sólido, reação química conhecida como "CURA", originando um material estrutural conhecido como "Fiberglass". Após a passagem pelo molde, estando a resina curada, a chapa já se encontra em condições de ser manuseada e serrada.

Por se tratar de processo contínuo de laminação, as dimensões dos perfis são limitadas apenas pelo transporte.

Pode-se pigmentar a resina Poliéster na cor desejada na aplicação final, tornando desnecessária qualquer pintura posterior, adicionando ao produto um acabamento estético, podendo ser explorado arquitetonicamente.

\subsection{Propriedades Mecânicas}

O processo de Pultrusão permite ajustar as propriedades mecânicas dos laminados, variando os tipos e as proporções de Fibras de Vidro de reforço. Por ser automatizado e pouco dependente de mão-deobra, o processo em questão, proporciona a laminação de peças de qualidade consistente, com pouca variabilidade (importante para a qualidade final do produto).

Os perfis pultrudados têm resistência mecânica específica à tração, flexão e compressão, aproximadamente 20 vezes 
superiores à do aço, com peso $80 \%$ menor que o do aço e $30 \%$ menor que o do alumínio. Sua densidade é de $1,9 \mathrm{~g} / \mathrm{cm} 3$, podendo ser considerada baixa, comparada a $7,9 \mathrm{~g} / \mathrm{cm} 3$ para o aço e 2,8g/cm 3 para o alumínio. Esses perfis não sofrem alterações ou ataques em ambientes corrosivos. A resistência à corrosão é inerente ao material, que dispensa pintura ou qualquer outro tipo de proteção. Mesmo sob diferentes temperaturas, o material é imune às intempéries. $\mathrm{O}$ perfil em plástico reforçado com fibras é material isolante, que não conduz corrente elétrica.

A grande liberdade de projeto dos elementos pultrudados permite a combinação de várias funções em uma única estrutura, facilitando montagens e reduzindo o investimento em moldes.

Os perfis em plástico reforçado com fibras praticamente não absorvem umidade. Este fato, aliado ao baixo coeficiente de dilatação térmica, faz com que mantenham sua forma e dimensões inalteradas em ampla faixa de temperatura, independente da umidade.

Suas dimensões não mudam quando submetidos a carregamentos de fadiga contínuos.

\section{Programa Experimental}

O programa experimental teve como objetivo mostrar a potencialidade do perfil em plástico reforçado com fibra de vidro na construção de treliça para cobertura. Foi baseado na confecção de três séries de treliças, variando o tipo de ligação das peças estruturais. Cada série foi formada por duas treliças de perfil pultrudados. Elas foram denominadas de acordo com a ligação estrutural utilizada. A série onde foi usada cola a base de "epóxi” nas ligações estruturais foi chamada de primeira. A outra, onde foi usado rebite nas ligações estruturais, foi chamada de segunda. A última série, aquela onde foi usada cola a base de "epóxi" e rebite, em conjunto, nas ligações estruturais foi chamada de terceira.

As séries tinham o objetivo de extrair resultados significativos, admitindo-se todos os resultados como favoráveis.

A viga em questão, treliça de cordas paralelas, foi baseada no modelo de SEIXAS.(1994). Para isso, foram construídas treliças com 3,00 m de vão livre por $23 \mathrm{~cm}$ de altura, conforme mostrado nas Figuras 1 e 2.

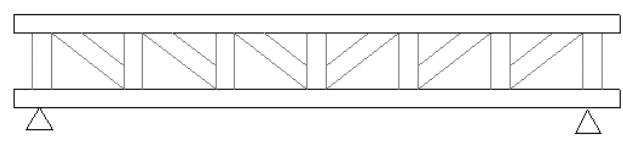

Figura 1 - Vista lateral da treliça

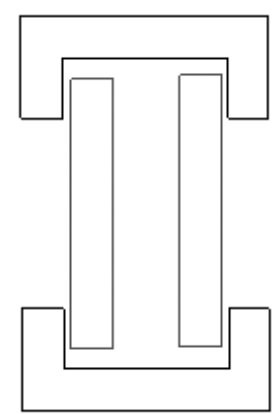

Figura 2 - Vista da treliça

\subsection{Programa de Ensaios}

\subsubsection{Preparação das Vigas}

As treliças foram montadas com perfis em " $U$ " de plástico reforçado, retirado da produção de escada de uma indústria.

O material recolhido foi limpo e preparado para o corte das peças componentes da treliça. Assim, os perfis em "U" foram cortados, numa bancada apropriada, com tamanhos adequados para as diagonais, os montantes e as cordas.

As peças foram cortadas com a serra tipo "Maquita". A operação foi feita com filete de água para evitar o excesso de pó durante o corte. Embora tenha se tomado esse cuidado, o operador ainda utilizou luvas, máscaras protetoras e roupas apropriadas. Após o corte das peças, houve necessidade de se lixar as partes separadas para retirar as saliências e sujeiras resultantes desta operação.

O próximo passo foi realizar uma pré-montagem das treliças, onde as posições de fixação das diagonais e dos montantes eram marcadas com antecedência e experimentadas antes da fixação definitiva.

De acordo com a Figura 2, foram fixados montantes e diagonais nas duas abas dos perfis usados para corda inferior e superior.

Com as peças já experimentadas, era iniciado o processo de montagem das treliças. A fixação foi feita peça a peça, tomando-se o cuidado de manter cada uma a sua posição, marcada quando experimentados inicialmente. Como foi necessário que a diagonais e os 
montantes estivessem nas duas abas dos perfis, usados como cordas, o outro lado só era fixado após a cura da cola a base de "epóxi", fixado no primeiro lado da treliça. Na série de vigas rebitadas, também se fez necessário uma pré-montagem das diagonais e dos montantes antes da fixação definitiva. Com os locais de fixação já marcados, foram executados dois furos, com furadeira elétrica, e fixados os rebites tipo "pop", dois em cada nó. A série de vigas rebitadas e coladas seguiu os mesmos procedimentos das séries anteriores. A ordem da confecção foi primeiro a fixação com cola a base de epóxi e, após a cura dos mesmos, foram introduzidos rebites tipo "pop", usando o mesmo processo descrito anteriormente.

\subsubsection{Ensaio das Vigas}

Os ensaios só tiveram inicio após a confecção de todas as treliças das três séries, mencionadas anteriormente.

As treliças foram então colocados na prensa, com vão de $3,00 \mathrm{~m}$, de acordo com a Figura 3, sendo aplicadas cargas até a desestabilização da viga.

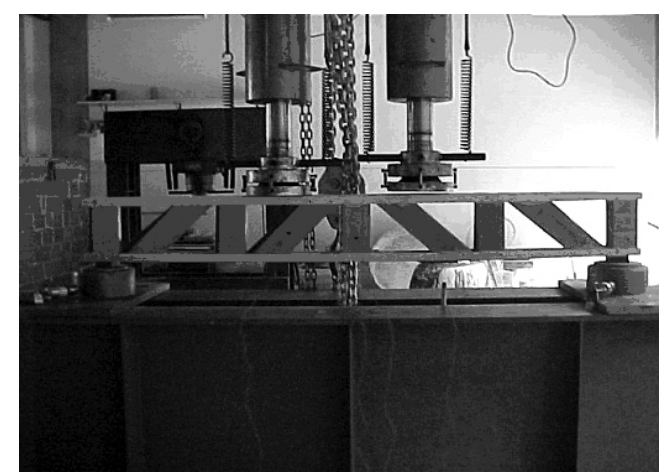

Figura 3 - Vista da prensa do laboratório da UFF no momento da aplicação da carga

Antes de iniciar a carga na treliça, foram instalados três sensores eletrônicos em cada uma delas, sendo: um na diagonal, outro na corda inferior e o último na corda superior.

Todos os esforços resultantes da aplicação das cargas na treliça são fornecidos por um programa computacional que é parte integrante de uma das prensa, existente no "LABORATÓRIO DE MATERIAIS DA ENGENHARIA CIVIL" da Universidade Federal Fluminense, no Campus Gragoatá em Niterói/RJ.

Os dados coletados foram compilados e elaborados gráficos de trabalho, onde se observa o comportamento das peças individualmente.

\section{Resultado dos Ensaios}

Como já foi dito anteriormente, os ensaios tiveram os seus resultados anotados e foram confeccionados os gráficos abaixo:

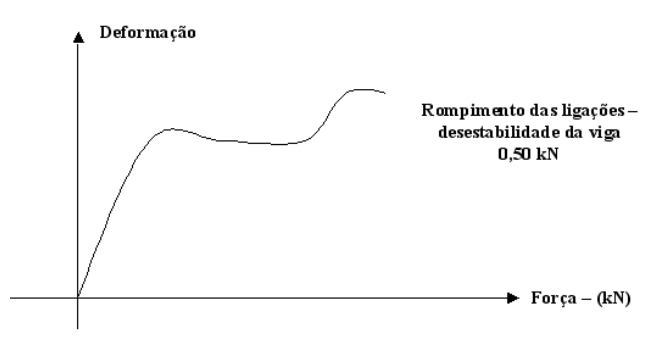

Gráfico 1 - Carga no Corpo de Prova Colado

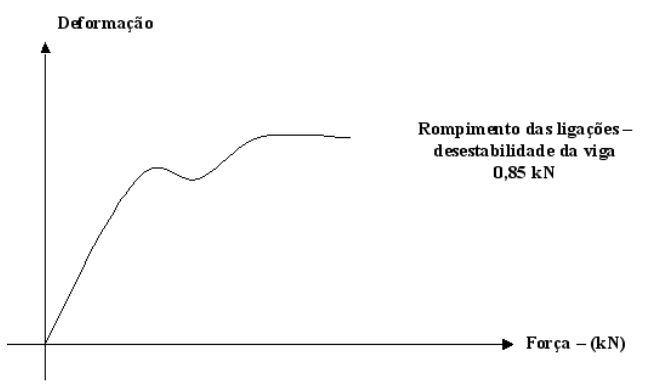

Gráfico 2 - Carga no Corpo de Prova Rebitado

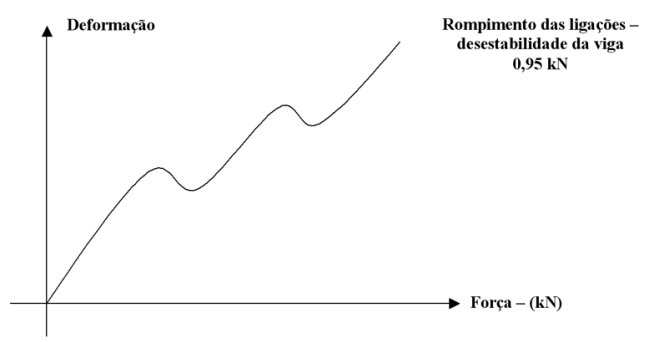

Gráfico 2 - Carga no Corpo de Prova Rebitado

\subsection{Análise dos Resultados}

De posse dos resultados obtidos nos ensaios realizados, é necessário todo cuidado para a obtenção dos valores, essa é, portanto, a fase em que se obtém subsídios para as conclusões e o aproveitamento de todo o trabalho.

A análise dos resultados desta pesquisa é baseada nos valores obtidos dos ensaios das vigas dos exemplares moldados e procura comparar com os valores obtidos em exemplares semelhantes de madeira e de perfis de aço.

O objetivo fundamenta-se em avaliar a potencialidade do emprego dos perfis pultrudado em treliças para telhado, montadas com perfis da produção de escada. Por este motivo, é necessário o prosseguimento do estudo, principalmente as ligações da peça, pois as mesmas em todas as provas de carga 
foram as primeiras a romper, ficando bem evidente que o perfil suporta um esforço bem maior.

Os resultados estão apresentados nos Gráficos 1, 2, e 3. Estes gráficos foram confeccionados com valores médios resultantes do ensaio de cada série das treliças.

Os gráficos foram traçados se baseando nas cargas aplicadas nas cordas, mostrando a média do ensaio das duas vigas coladas, das duas vigas rebitadas e das duas vigas coladas e rebitadas.

\subsubsection{Ligação Colada}

Os resultados apresentados no Gráfico 1 mostram as cargas e as respectivas deformações correspondentes na viga ensaiada.

Como o corpo de prova foi construído com um só tipo de perfil, ou seja, foi usado o mesmo tipo para corda, diagonal e montante, percebeu-se que os pontos mais frágeis seriam as ligações. Isso resultou num cuidado maior na montagem das treliças, procurando fixar as diagonais e os montantes na aba do perfil $\mathrm{U}$, sem apoiá-los diretamente sobre a corda superior e inferior, possibilitando a verificação da resistência das ligações, o ponto mais frágil da viga.

As oscilações mostradas no Gráfico em questão representam a ruptura de uma das ligações, o que proporcionava um novo equilíbrio da viga. Além de mostrar a carga de ruptura de das ligações, ela indica a deformação correspondente da corda.

As ligações foram soldadas com adesivo epóxi Sikadur 32 (Resina - Epóxi (Araldite) MC 130, Endurecedor (Araldite) FD 137e Aerosil (Composto à base de Silicato) seguindo as especificações do fabricante, ou seja, a cada 100 gramas de cola adicionar 20 gramas de Aerosil).

Principais conclusões da viga colada:

- O perfil de plástico reforçado apresenta uma ótima elasticidade observada nos ensaios, onde a viga foi carregada, proporcionando uma flecha e, ao se retirar à carga, ela voltou a posição original;

- A maioria das cargas apresentada foi relativa ao rompimento das ligações, neste caso, colada. Nos casos em que houve rompimento da aba do perfil, as cargas atuantes foram bem maiores em relação as que romperam ligações;

- Pela carga aplicada, a treliça com ligações coladas pode ser usada em coberturas de edificações residenciais, comercias e industriais;

\subsubsection{Ligação Rebitada}

Os resultados apresentados no Gráfico 2 mostram as respectivas deformações resultantes do carregamento das vigas, com ligação rebitada.

Cada valor mostrado indica a carga de ruptura de uma das ligações e a deformação correspondente devido à mesma.

As ligações realizadas com rebite seguiram os espaçamentos mínimos exigidos para a utilização do parafuso em perfil metálico. Os rebites usados foram do tipo "POP" de 3,2 $\mathrm{x} 15 \mathrm{~mm}$.

Uma das dificuldades enfrentadas nas ligações com rebites foi à existência de outros furos nas peças, provenientes da fabricação da escada, que contribui para o enfraquecimento da seção e o rompimento mais rápido da ligação.

Principais conclusões da viga rebitada:

- A treliça rebitada apresentou certa instabilidade, pois o tipo de ligação usada, com quatro rebites em cada nó, fez com que elas se tornassem rótulas, após o rompimento de um deles no carregamento;

- O critério adotado para o ensaio permitiu que o carregamento continuasse após o rompimento de um ou mais rebites das ligações, continuando até a peça se desestabilizar por completo;

- Esse tipo de ligação não deve ser usado em qualquer lugar, principalmente em ambientes industriais, pois pode haver uma reação química, enfraquecendo o rebite.

\subsubsection{Ligação Mista}

Foi a viga que suportou maiores cargas, pois a associação do rebite com a cola a base de "epóxi" apresentou boa resistência aos esforços.

Os resultados apresentados no Gráfico 3 mostram as cargas, com as respectivas deformações apresentadas nos mesmos. 
A execução de cola e rebite no mesmo nó permitiu um acréscimo de carga atuante na peça o que mostra que a ligação deve ser executada dessa forma.

A ligação foi executada usando primeiro a cola, fixando um lado primeiro, depois de curado, era fixado o outro. Só após a cura do segundo lado fixado e que era colocado o rebite.

A execução dos rebites seguiu também o mesmo procedimento das vigas só rebitas, ou seja, os furos eram pré-marcados e, através de uma furadeira elétrica, eram executados furos e, em seguida, os rebites eram fixados com ferramenta apropriada.

$\mathrm{O}$ ensaio com vigas confeccionadas com ligações mistas seguiu o mesmo procedimento adotado nas outras peças com outras ligações. Da mesma forma, após o rompimento de uma ligação, o ensaio continuava com o carregamento até a desestabilização total da treliça, seja através do rompimento do perfil, flecha excessiva da viga ou rompimento de várias ligações da peça.

Principais conclusões da viga colada e rebitada:

- A treliça mista apresentou uma estabilidade maior que as rebitadas;

- Neste caso, quando os rebites rompiam, a cola continuava a resistir até também romper. Assim, houve um acréscimo de carga na treliça;

- A peça com ligação mista se mostrou apropriada para além de suporte para a cobertura, resistir também algumas cargas extras;

\section{Considerações Finais}

Os perfis de plástico reforçados com fibra de vidro são uma realidade nos dias de hoje, principalmente na Europa e nos Estados Unidos. Lá, existem algumas obras em perfil de plástico reforçado com fibra, como por exemplo, uma passarela construída na cidade de Kolding, Dinamarca. Esta obra recebeu o prêmio "Aplicação do ano" da AVK (Associação de Plástico Reforçado da Alemanha), em 1997.

No Brasil, já existem algumas aplicações do plástico reforçado com fibra de vidro na construção civil, como: tubos para escoamento de águas, caixas d'água, telhas, coberturas das quadras de esporte do Pan-2007/ Rio de Janeiro, em prédios de utilização DryWall, que são as aplicações mais conhecidas do plástico reforçado. Assim, a proposta deste trabalho é mostrar a potencialidade da aplicação do material na construção de treliças para coberturas.

As construções atuais têm cada vez mais necessidade de resistir aos meios agressivos e oferecer simplicidade e pouca manutenção aos seus usuários, além de ser leve e resistente.

Assim, nas habitações populares tem havido dificuldades de executar uma casa que atenda as necessidades mencionadas acima. As técnicas utilizadas são, na maioria das vezes, antiquadas e, por isso, é muito raro encontrar uma edificação popular de qualidade.

Nas construções industriais, sempre há necessidade de grandes vãos sob área coberta para facilitar a movimentação no seu interior. $\mathrm{O}$ material mais empregado atualmente para o suporte destas coberturas é o aço, através de diversos tipos de perfis, que compõem as treliças, ou seja, tipos de vigas compostas de cordas, diagonais e montantes, utilizadas quando se tem necessidade de vencer grandes vãos, sem pilares intermediários, com elevado carregamento.

As treliças atuais, de acordo com o local de utilização, vão, tipos de telhado, podem ser de: madeira, metálica, alumínio, concreto ou de outro material qualquer.

Os materiais mais usados para a construção destas vigas são a madeira e o aço.

A treliça em madeira é a mais antiga a ser usada. Atualmente, tem sua utilização reduzida em função do alto custo da madeira, limitação do vão livre, desgaste do material através de ataque de insetos e da umidade, elevado peso próprio etc. Há alguns anos, a treliça em madeira vem sendo substituída pela treliça em perfil de aço.

A treliça em perfil de aço surgiu como alternativa à treliça em madeira. Apesar de apresentar algumas vantagens em relação à madeira, o perfil de aço ainda tem várias dificuldades a serem vencidas. $O$ elevado custo de manutenção, a baixa resistência aos ataques químicos, elevado peso-próprio que dificulta a montagem da estrutura, confiabilidade da 
ligação estrutural, principalmente quando esta for através de solda, são alguns problemas enfrentados pela estrutura de aço nos dias de hoje.

A treliça em perfil pultrudado apresenta várias vantagens em relação aos demais materiais de uso comum. A passarela da cidade de Kolding na Dinamarca, mostra com clareza algumas vantagens. Ela mede 40 $\mathrm{m}$ de comprimento por $3 \mathrm{~m}$ de largura, com isso, permite a travessia de pedestres, ciclistas e motociclistas. Ela foi projetada para suportar cargas de até $500 \mathrm{kgf} / \mathrm{m} 2$. Esta resistência é provida por um passadiço que pesa somente 12 toneladas. Em aço, essa mesma estrutura pesaria 28 toneladas e em concreto, 90 toneladas. Aleveza dos compósitos possibilitou a montagem da ponte em apenas 18 noites, minimizando assim a interrupção do tráfico da rodovia. Outras grandes vantagens são: a grande durabilidade dos compósitos, que no caso da passarela, espera-se que nos próximos 50 anos ela venha sofrer apenas manutenção limpeza e pintura e a outra grande vantagem é a resistência aos ataques químicos, pois Kolding é uma cidade que faz limite com o oceano, assim, a passarela em perfil de plástico resiste bem a influência marítima.

Este estudo mostra a potencialidade de uma treliça em perfil pultrudado para ser usada em estruturas para coberturas das edificações. Baseado em várias características, como: pequeno peso-próprio, boa resistência aos ataques químicos, grande resistência ao carregamento etc, foram montadas treliças de cordas paralelas para carregamento no laboratório. A metodologia utilizada foi definida da seguinte forma:

- Construção de seis treliças de cordas paralelas, utilizando o perfil pultrudado fabricado para ser usado em escadas manuais;

- As cordas, as diagonais e os montantes foram feitos com o mesmo tipo de perfil;

- As ligações variaram, sendo: duas vigas com ligações coladas, duas com ligações rebitadas e as outras duas com ligações mistas (rebitada e colada);

- As vigas forma colocadas na prensa e carregadas até a desestabilização da mesma, ou uma flecha excessiva.

Após a realização dos ensaios, analisando os resultados obtidos, é possível concluir que é possível a utilização de treliças em PRFV em estruturas para coberturas e telhados. Além de apresentar resistência ao carregamento igual ou superior a madeira, ainda tem muitas vantagens, como: dispensa acabamento, apresenta baixa manutenção entre outras. Em relação ao aço, também resistência igual, ou superior, e tem menor peso-próprio, boa resistência aos ataques químicos, também dispensa necessidade de acabamento, tem baixa manutenção.

Os demais materiais, embora com utilização restrita, também apresentam enormes desvantagens em relação aos perfis pultrutados. O concreto, por exemplo, apresenta peso-próprio muito maior em relação ao do PRFV, sem falar na dificuldade de execução e no tempo de construção. $O$ bambu tem dificuldades de estabilidade em função da dimensão do mesmo. O alumínio, apesar de apresentar pequeno peso próprio, boa resistência aos ataques químicos, possui um alto custo e tem problemas nas ligações estruturais.

\section{Referências}

CORNETTI, L. e Outros, Análise numérico e experimental de um modelo de treliça mista aço-madeira. - VII Encontro Brasileiro em madeiras e estruturas de madeira - Uberlândia, 2002. Capturado na internet em abril de 2004.

COSTA, M. A. B. da A técnica do entalhe sobre a madeira. www.entalhenamadeira. com.br. Capturado na internet em abril de 2004

EPOXY, Adesivos Epoxy São Paulo: Revista do Plástico Reforçado, 2003.

MATTHEWS, F. L., et. RAWLINGS, R. D. Composite Materials: Engineering and Science. London: Chapmam \& Hall, 1994.

MORAIS, W. A . e ALMEIDA, J. R. M. Efeitos de impactos repetidos de baixa energia em compósitos Pultrudados .São Paulo: Publicação da Universidade de São Carlos, 2001

MOREIRA, L. E. Desenvolvimento de Estruturas Treliçadas Espaciais de Bambu, 
Tese de Mestrado, DEC, PUC- Rio, Rio de Janeiro, Brasil, 1991. Capturado na internet em março de 2004.

UEDA, K., Bamboo production and utilization, present and future. Kyoto Japão - XVII - UFRO world congress, 1981. Capturado na internet em março de 2004.

WILIANS, P., Anotações de sala de aula, Teoria das Estruturas - Teoria das Treliças. Internet, 2001. Capturado na internet em fevereiro de 2004.

Informações bibliográficas:

Conforme a NBR 6023:2002 da Associação Brasileira de Normas Técnicas (ABNT), este texto científico publicado em periódico eletrônico deve ser citado da seguinte forma:

GUIMARÃeS, Alexandre José de Athayde. Estudo dos Perfís Compostos em Fibra de Vidro pelo Processo de Fabricação por Pultrusão Combinando as Vantagens do Plástico com a Madeira e o Aço . Cadernos UniFOA, Volta Redonda, ano 2, no. 5, dez. 2007. Disponível em: <http://www.unifoa.edu. br/pesquisa/caderno/edicao/05/22.pdf $>$ 